\title{
SUPPORTING SOMEONE TO QUIT SMOKING
}

Quitting smoking is the best investment a smoker can make to improve their health. Making the decision to quit is a big one. If you're supporting someone to quit it is important to recognise that they have to want to do it for their own reasons, and not because of pressure from a friend or family member. Take your cue from the person who is quitting and be strategic in the support that you offer.

\section{UNDERSTANDING WHY PEOPLE SMOKE}

There are many reasons why people smoke. Nicotine is the source of addiction to tobacco, and cigarettes are as addictive as heroin or cocaine. ${ }^{1}$ Some people associate the craving for a cigarette with a particular behaviour, such as consuming alcohol, food or coffee. Others crave a cigarette when certain feelings arise, such as boredom or anxiety. Some people smoke because it can be social, or they may like the taste or the actions of smoking a cigarette.

After inhaling tobacco smoke the nicotine reaches the brain in about 10 seconds. ${ }^{2}$ Once the nicotine has attached itself to special sites in the brain, relaxing chemicals are released. But this effect only lasts for a short time and then the nicotine needs to be topped up. One of the reasons people continue to smoke is because they enjoy the temporary feeling of the relaxing chemicals. The fact sheet Nicotine and other poisons has more information.

\section{UNDERSTANDING WHY PEOPLE WANTTO QUIT}

There are many reasons why people want to quit smoking. For some people smoking starts to cost them too much money. It also affects their health and fitness. Other smokers say that they have been influenced by antismoking campaigns or that friends and family have asked them to quit. Whatever the reasons for quitting, the important thing is that the smoker has decided to quit for their own reasons. One of the most important factors in being successful in quitting is the smoker's motivation.

\section{A REALITY CHECK}

The benefits gained as a non-smoker outweigh the shortterm difficulties of quitting. However, someone who is quitting smoking may appreciate your support during the first two weeks, as this is the time when they are most likely to return to smoking. Becoming a non-smoker is a process and takes time.
Many people make several quit attempts before they are successful. With each attempt they learn more about how their body reacts to going without the nicotine in cigarettes and adjusting to the social side of becoming a brand new non-smoker.

\section{A QUIT PLAN}

A quit plan is integral to the quitting process. You can assist a person trying to quit by discussing the elements of a quit plan with them:

- setting a date to quit smoking;

- thinking about nicotine replacement therapies (NRT);

- knowing the triggers and planning the strategies;

- a support network;

- smoke free zones;

- planning rewards;

- being supportive.

The fact sheet Getting ready to quit has more information.

\section{MANAGING THE CHALLENGING TIMES}

The first three days after quitting are the most difficult. This is because the person quitting smoking is going through nicotine withdrawal. Keep the messages positive. Some former smokers say that they thought about their experiences of nicotine withdrawal in a positive way by calling them 'recovery symptoms' and thinking about the improvements in their health.

A 'craving' for nicotine may last only a few minutes but a person who has just quit may feel more tired or anxious than usual. This is an important time to listen carefully and provide realistic messages, such as taking it one craving at a time, one day at a time. The fact sheet Nicotine dependence and withdrawal has more information.

\section{LIMITING ALCOHOL}

For people quitting smoking it's a good idea to avoid alcohol during the first two weeks. ${ }^{2}$ First, alcohol tends to lower one's inhibitions, making it more difficult to maintain the determination not to smoke. Another reason is that it is a common habit to combine a drink and a smoke, so having a drink with friends who smoke may trigger cravings. Instead of meeting for drinks you could suggest an alternative such as the cinema or an outing to another smoke-free place such as a restaurant, a theatre, a bowling alley, etc. 


\section{KNOWING THE NICOTINE AND CAFFEINE LINK}

As the body removes nicotine it absorbs more caffeine. It's a good idea to reduce the amount of tea, coffee and cola drinks by half. ${ }^{2}$ An increase in caffeine levels for someone who has just quit smoking may add to feelings of restlessness or insomnia.

\section{A FINAL NOTE}

Coping with nicotine withdrawal is a challenge, especially in the first few days. The long-term benefits of quitting will definitely outweigh the short-term difficulties. Stay positive and be kind to yourself while you're experiencing 'recovery symptoms'.
If you would like to quit smoking contact the Quitline on 131848 , speak with your doctor or pharmacist, or visit the website www.quitnow.info.au.

\section{REFERENCES}

1. Royal College of Physicians. Nicotine Addiction in Britain. A Report of the Tobacco Advisory Group of the Royal College of Physicians; London: Royal College of Physicians, 2000.

2. Garvey AJ, Bliss RW, Hitchcock JL et al. Predictors of smoking relapse among self-quitters: A Report of the Normative Aging Study. Addict Behav 1993; (17): 367-377.

This fact sheet is one of a series on tobacco and health related issues produced by the Tobacco and Health Branch of the NSW Department of Health. The fact sheets respond to frequently asked questions and are designed to be used by both consumers and health professionals to help people to quit smoking.

The fact sheets can be accessed through the NSW Department of Health's website at www.health.nsw.gov.au/public-health/health-promotion/tobacco/facts/index.html. 